\title{
Silencing Livin improved the sensitivity of colon cancer cells to 5-fluorouracil by regulating crosstalk between apoptosis and autophagy
}

\author{
SHUAI LIU $^{1 *}, \mathrm{XIN} \mathrm{LI}^{1 *}, \mathrm{QING} \mathrm{LI}^{1,2}$, HONGJUN LIU $^{3}, \mathrm{YULONG} \mathrm{SHI}^{3}$, \\ HONGQING ZHUO ${ }^{3}$, CHENSHENG $\mathrm{LI}^{3}$ and HUIJUAN ZHU ${ }^{4}$
}

\begin{abstract}
${ }^{1}$ Department of Urology, Shandong Provincial Hospital Affiliated to Shandong University, Jinan, Shandong 250012; ${ }^{2}$ Department of Urology, Yucheng People's Hospital, Yucheng, Shandong 251200; ${ }^{3}$ Department of Gastrointestinal Surgery, Shandong Provincial Hospital Affiliated to Shandong University, Jinan, Shandong 250012; ${ }^{4}$ Department of Pharmacy Intravenous Admixture Services, Kaifeng Children's Hospital of Henan Province, Kaifeng, Henan 475000, P.R. China
\end{abstract}

Received August 1, 2016; Accepted October 13, 2017

DOI: $10.3892 / \mathrm{ol} .2018 .8282$

\begin{abstract}
Colorectal cancer (CRC) is the third most common cause of cancer-associated mortality worldwide. Currently, 5-fluorouracil (5-FU) remains a widely used chemotherapeutic drug in the treatment of CRC; however, 5-FU resistance during treatment has become a common problem. Livin, a member of the inhibitor of apoptosis protein family, is considered to be associated with tumor resistance to chemotherapy. In the present study, Livin-silenced cells were generated by introducing a lentivirus into HCT116 and SW620 colon cancer cell lines. Acridine orange/ethidium bromide staining was used as an indicator of cell death. Western blot analysis was performed to detect protein expression levels, and transmission electron microscopy was used to assess autophagy. The half-maximal inhibitory concentration of 5-FU in colon cancer cells was evaluated using a Cell Counting Kit- 8 assay. The results of the present study confirmed that silencing Livin significantly enhanced colon cancer cell death in the presence of 5-FU, increased expression levels of various apoptosis- and autophagy-associated proteins and augmented chemotherapeutic sensitivity to 5-FU. Furthermore, the present study demonstrated that this effect may be reversed when autophagy or apoptosis was inhibited, indicating that apoptosis and autophagy were involved in this process. The protein kinase B signaling pathway and B-cell lymphoma-2 expression levels significantly decreased
\end{abstract}

Correspondence to: Dr Chensheng Li, Department of Gastrointestinal Surgery, Shandong Provincial Hospital Affiliated to Shandong University, 324 Jingwu Road, Jinan, Shandong 250012, P.R. China

E-mail: chensheng76@163.com

${ }^{*}$ Contributed equally

Key words: apoptosis, autophagy, chemotherapeutic sensitivity, colon cancer, Livin following Livin knockdown, suggesting they may contribute to the regulation of apoptosis and autophagy crosstalk, which caused the Livin knockdown-induced cell death observed.

\section{Introduction}

Colorectal cancer (CRC) is one of the most common types of malignancies in Western countries, causing $~ 500,000$ cancer-associated mortalities annually worldwide (1). Despite undergoing surgical resection, nearly $50 \%$ of patients do not respond to chemotherapy due to drug resistance (2). Previous studies have revealed that this may be due, at least in part, to anti-apoptotic responses (3-5).

The inhibitor of apoptosis protein (IAP) family is crucial to the anti-apoptotic responses of tumor cells (6). Livin, an important member of IAP, is considered to negatively regulate apoptosis-associated proteins and prevent apoptosis. It is strongly expressed in numerous common human neoplasms including CRC and lung cancer (7,8). Overexpression of Livin in tumors is associated with resistance to chemotherapy and radiotherapy, increased tumor recurrence and decreased patient overall survival (9-11). In CRC tissues, Livin expression levels are significantly increased and considered to be an independent prognostic factor (12).

In the past three decades, 5-fluorouracil (5-FU) chemotherapy has been the primary choice for the adjuvant treatment of CRC, although its resistance in the course of treatment has become a common problem. Briefly, 5-FU is an analog of uracil with a fluorine atom at the $\mathrm{C}-5$ position in place of hydrogen. It inhibits thymidylate synthase and influences uracil metabolism to induce apoptosis in cancer cells $(13,14)$. Previous studies have revealed that Livin serves a role in 5-FU resistance, and that the knockdown of Livin expression in cancer cell lines facilitates 5-FU-induced cell apoptosis $(15,16)$. However, the mechanisms underlying Livin-mediated reversal of 5-FU chemoresistance have not yet been fully elucidated.

Apoptosis, also known as type I cell death, is a well-researched form of programmed cell death that involves the rapid demolition of cellular structures and organelles 
via the activation of catabolic enzymes (17). Autophagy is a conserved catabolic process in which cellular contents are degraded in lysosomes (18). Autophagy is considered to serve an important role in tumor development and chemoresistance (19). Previous studies have demonstrated that autophagy may serve a beneficial or detrimental effect on cancer cells, depending on the response to environmental stressors (20). With regard to benefits, autophagy provides the metabolites and ATP required for cell survival upon exposure to diverse environmental stressors, including treatment with chemotherapeutic agents, endoplasmic reticulum stress and hypoxia (21). Conversely, in certain cases, autophagy can lead to cell death by lysosome-mediate cell degradation (a distinct form of cell death compared with apoptosis) (22). Autophagy and apoptosis serve important roles in oncogenesis and tumor progression in mammals; they may be triggered by common upstream signals, resulting in combined autophagy and apoptosis $(23,24)$. In other instances, their occurrence may be mutually exclusive. For example, researchers have demonstrated autophagy-mediated removal of protein of aggregates and harmful organelles, which induced inhibition of cell apoptosis (25). Despite efforts, the crosstalk between autophagy and apoptosis remains unclear. Previous studies have suggested the involvement of B-cell lymphoma-2 (Bcl-2)-beclin-1 interaction (25). In more recent studies, protein kinase B (Akt) was hypothesized to be involved in the crosstalk between apoptosis and autophagy (26). The present study revealed that apoptosis and autophagy were triggered by two common upstream signals, specifically $\mathrm{Bcl}-2$ and the Akt signaling pathway.

\section{Materials and methods}

Antibodiesanddrugs.Anti-Livin,anti-Schizontmembrane-associated cytoadherence protein (SMAC), anti-light chain 3 (LC3), anti-actin, anti-P62, anti-Bcl-2 and anti-caspase-3 antibodies were purchased from Abcam (Cambridge, UK); anti-phosphorylated (p)-Akt, anti-total (T)-Akt were purchased from Cell Signaling Technology, Inc. (Danvers, MA, USA). The 5-FU, autophagy inhibitor 3-methyladenine (3-MA) and apoptosis inhibitor benzyloxycarbonyl-Val-Ala-Asp fluoromethylketone (z-VAD-FMK) were purchased from Sigma-Aldrich (Merck KGaA, Darmstadt, Germany).

Cell lines and cell culture. HCT116 and SW620 human colon carcinoma cell lines were obtained from the Cell Bank of the Chinese Academy of Sciences (Shanghai, China) and maintained in RPMI-1640 (Gibco; Thermo Fisher Scientific, Inc., Waltham, MA, USA) culture medium supplemented with $10 \%$ fetal bovine serum and $1 \%$ penicillin/streptomycin. All cells were grown in a humidified incubator at $37^{\circ} \mathrm{C}$ with $5 \% \mathrm{CO}_{2}$.

Short hairpin (sh)RNA synthesis and construction of Livin shRNA lentiviral vectors. The double stranded RNA sequences, simultaneously aimed at both Livin mRNA isomers (GenBank accession nos. NM_139317 and NM_022161), were designed as previously described $(27,28)$. The sense strand was 5'-CAGGAGAGAGGTCCAGTCCAGTCTGA-3' and the antisense strand was 5'-TCAGACTGGACCTCTCTCCTG-3'. They were synthesized by Shanghai GeneChem Co., Ltd. (Shanghai, China). Their connection to the lentiviral vector
pGCL-GFP (Shanghai GeneChem Co., Ltd.) was verified by Shanghai GeneChem Co., Ltd. using polymerase chain reaction (PCR) and DNA sequencing (data not shown). Briefly, the products were transformed to fresh component bacteria $E$. coli (Shanghai GeneChem Co., Ltd.) and 10 clones were selected for each plasmid. PureLink ${ }^{\mathrm{TM}}$ Genomic DNA Purification kit (Thermo Fisher Scientific, Inc.) was used for DNA extraction and purification prior to being subjected to PCR amplification (forward primer, 5'-CGCACGGCACAAAGACGA-3' and reverse primer, 5'-GTCAGTTCCTGCTCCGGTCAA-3'). Taq DNA Polymerase (Thermo Fisher Scientific, Inc.) was used for DNA amplification. The thermocycling conditions were as follows: $95^{\circ} \mathrm{C}$ for $5 \mathrm{~min}$, followed by 25 cycles of $95^{\circ} \mathrm{C}$ for $30 \mathrm{sec}, 55^{\circ} \mathrm{C}$ for $60 \mathrm{sec}, 72^{\circ} \mathrm{C}$ for $60 \mathrm{sec}$, and a final extension at $72^{\circ} \mathrm{C}$ for $7 \mathrm{~min}$. The products were identified by $2 \%$ agarose gel electrophoresis and further determined by DNA sequencing (Shanghai GeneChem Co., Ltd.).

Transfection. The verified lentiviral vector was packaged by 293T packaging cells (Shanghai Gefan Biotechnology Co., Ltd., Shanghai China), and vector particles were concentrated and purified to reduce toxicity. These lentiviral vectors infected HCT116 and SW620 cells when the cells achieved a confluence of $\sim 80 \%$ following incubation at $37^{\circ} \mathrm{C}$ for $48 \mathrm{~h}$. Expression of the green fluorescent protein reporter gene on the lentivirus was observed 4-5 days after infection (multiplicity of infection $=50$ ). Cells were collected with a transfection efficiency $>80 \%$. Further experiments were performed 6-10 days after transfection. The cells into which the lentivirus-shLivin was transfected were named the shLivin group, the cells transfected with the negative control (NC) shRNA were named the NC group, and the untransfected HCT116 and SW620 cells were named the control group.

Reverse transcription-quantitative $(R T-q) P C R$ analysis. Livin expression levels in HCT116 and SW620 cell lines were determined by RT-qPCR analysis, using the standard methods previously described (29). Total RNA was extracted from HCT116 and SW620 cell pellets prepared by centrifugation at $500 \mathrm{x}$ g for $5 \mathrm{~min}$ at room temperature using TRIzol ${ }^{\circledR}$ reagent (Takara Biotechnology Co., Ltd., Dalian, China). Reverse transcription was performed using the Prime Script Strand cDNA Synthesis kit (Takara Biotechnology Co., Ltd.) according to the manufacturer's protocol. cDNA were amplified using SYBR Premix Ex Taq (Takara Biotechnology Co., Ltd.). The PCR primer sequences were as follows: Livin forward, 5'-CGC ACGGCACAAAGACGA-3' and reverse, 5'-GTCAGTTCC TGCTCCGGTCAA-3'; $\beta$-actin forward, 5'-AGCCATGTA CGTAGCCATCC-3' and reverse, 5'-CTCTCAGCTGTGGTG GTGAA-3'. PCR thermocycling conditions were set as follows: Pre-denaturing at $95^{\circ} \mathrm{C}$ for $30 \mathrm{sec}$, denaturing at $95^{\circ} \mathrm{C}$ for $5 \mathrm{sec}$, annealing at $60^{\circ} \mathrm{C}$ for $34 \mathrm{sec}$ with 40 cycles, denaturing at $95^{\circ} \mathrm{C}$ for $15 \mathrm{sec}$, annealing at $60^{\circ} \mathrm{C}$ for $60 \mathrm{sec}$, and $95^{\circ} \mathrm{C}$ for a final $15 \mathrm{sec}$. PCR was performed using the Mastercycler nexus (Eppendorf, Hamburg, Germany). Data were analyzed using the comparative $\mathrm{Cq}$ method $\left(2^{-\Delta \Delta \mathrm{Cq}}\right)$ (30). Three independent experiments were performed for each clone.

Western blot analysis. Western blot analysis was performed as previously described (31). The cells were homogenized 
in radioimmunoprecipitation assay lysis buffer (Thermo Fisher Scientific, Inc.) and heated to $100^{\circ} \mathrm{C}$ for $10 \mathrm{~min}$ prior to analysis. Protein concentration is performed using the Bradford assay (Bio-Rad Laboratories, Inc., Hercules, CA, USA). In total, $30 \mu \mathrm{g}$ of protein mixture from cells was loaded per lane and separated by electrophoresis on an SDS-PAGE (10\% gel). Proteins were then transferred to nitrocellulose blotting membranes. Membranes were blocked for $1 \mathrm{~h}$ with $5 \%$ milk. The membranes were then blotted with anti-Livin (cat. no. ab97350; 1:1,000), anti-LC3 (cat. no. ab51520; 1:1,000), anti-p62 (cat. no. ab91526; 1:1,000), anti-caspase-3 (cat. no. ab13847; 1:1,000), anti-SMAC (cat. no. ab8115; 1:1,000), anti-p-Akt (cat. no. ab81283; 1:1,000), anti-Akt (cat. no. ab179463; 1:1,000), anti-Bcl-2 (cat. no. ab59348; 1:1,000 diluted) and anti-actin (cat. no. ab1801 1:1,000 diluted) which were all purchased from Abcam (Cambridge, UK) at $4^{\circ} \mathrm{C}$ over night. After washing three times with TBST (Thermo Fisher Scientific, Inc., Waltham, MA, USA), membranes were incubated with corresponding horseradish peroxidase-conjugated secondary antibodies (goat anti-rabbit; cat. no. ab6721; 1,5,000; Abcam) for $2 \mathrm{~h}$ at room temperature. Protein densitometry values were performed using an open source image-processing program Image J 1.46r (National Institutes of Health, Bethesda, MD, USA) according to a protocol described previously (32). The relative protein expression levels in different cell lines were normalized to $\beta$-actin. Three independent experiments were performed for each clone.

Cell viability assay. Cell viability was assessed using a Cell Counting Kit-8 (CCK-8; Dojindo Molecular Technologies, Inc., Kumamoto, Japan) assay, as described previously (33). Cells were seeded $\left(5 \times 10^{3}\right.$ cells/well) in 96-well microplates and grown in humidified incubator (at $37^{\circ} \mathrm{C}$ and $5 \% \mathrm{CO}_{2}$ ) overnight. Various concentrations of 5-FU $(10,20,40,80$ and $100 \mu \mathrm{M})$ were used to determine the concentration that produced the optimal HCT116 and SW620 cell response, following incubation for $24 \mathrm{~h}$. The concentrations of 5-FU that promoted a half-maximal growth inhibition $\left(\mathrm{IC}_{50}\right)$ are presented as the mean \pm standard deviation (SD), derived from triplicate samples of three independent experiments. The roles of autophagy and apoptosis in the Livin knockdown-induced recovery of 5-FU sensitivity were also further defined. In this regard, following Lv-sh Livin transfection, HCT-116 and SW620 cells were pretreated with an autophagy inhibitor (3-MA, $3 \mathrm{mM}$ ) at $37^{\circ} \mathrm{C}$ for $2 \mathrm{~h}$, or an apoptosis inhibitor (Z-VAD-FMK, $40 \mu \mathrm{M})$ at $37^{\circ} \mathrm{C}$ for $1 \mathrm{~h}$ prior to 5-FU $(20 \mu \mathrm{M})$ treatment, as previously described $(34,35)$.

Acridine orange (AO)/ethidium bromide $(E B)$ double staining . The DNA binding dyes AO and EB can be used for the morphological detection of cell death (36). A cocktail of EB and AO $(100 \mu \mathrm{g} / \mathrm{ml})$ was prepared in PBS. Following treatment with 5 -FU $(20 \mu \mathrm{M})$ at $37^{\circ} \mathrm{C}$ for $24 \mathrm{~h}$, the cells were washed twice with PBS, followed by replacement with fetal bovine serum (Gibco; Thermo Fisher Scientific, Inc.). Following $30 \mathrm{~min}$ incubation at $37^{\circ} \mathrm{C}$, the cells were washed again with PBS, stained with $\mathrm{AO} / \mathrm{EB}$, and incubated at $37^{\circ} \mathrm{C}$ for $30 \mathrm{~min}$ in the dark. The cells were washed with PBS and analyzed by fluorescent microscopy (magnification, x200) (36). The cell death rate $(\%)$ was calculated as the percentage of positively stained cells, namely the number of cells undergoing programmed cell death (per 100 cells). Three independent experiments were performed for each clone.

Lactate dehydrogenase ( $L D H)$ assay. To further investigate the effect of Livin-knockdown on the response of colon cancer cells to 5-FU, an LDH assay was performed. LDH release from HCT116 and SW620 cells was determined using the LDH Cytotoxicity Detection kit-PLUS (Roche Applied Science, Penzberg, Germany), according to the manufacturer's protocol. Briefly, cells were seeded in 96-well plates and cultured at $37^{\circ} \mathrm{C}$ for $24 \mathrm{~h}$ with $20 \mu \mathrm{M} 5-\mathrm{FU}$. The percentage of $\mathrm{LDH}$ released from the treated cells was calculated by comparing it with the maximum release obtained with $2 \%$ Triton X-100 treatment (positive control) and spontaneous LDH release (mock-treated cells considered as a negative control), as follows: Cytotoxicity $(\%)=($ experimental value - low control $) /($ positive control - low control) x100.

Transmission electron microscopy. The colon cancer cells were seeded into 6 -well plates at $37^{\circ} \mathrm{C}$ for $48 \mathrm{~h}$ and then fixed in $3 \%$ glutaraldehyde in $0.1 \mathrm{M}$ cacodylate buffer (Electron Microscope Sciences, Hatfield, PA, USA) at $37^{\circ} \mathrm{C}$ for $1 \mathrm{~h}$. Following fixation, the samples were post-fixed in $1 \%$ osmium tetraoxide in the same buffer at $37^{\circ} \mathrm{C}$ for $30 \mathrm{~min}$. Ultra-thin sections were then observed by transmission electron microscopy (magnification, x12,000).

Statistical analysis. Statistical analyses were performed using the GraphPad Prism version 5.0 (GraphPad Software, Inc., La Jolla, CA, USA). One-way analysis of variance (ANOVA) or two-way ANOVA, with Tukey's or Bonferroni post hoc tests, were utilized to analyze the differences between groups. Data are presented as the mean \pm standard error. $\mathrm{P}<0.05$ was considered to indicate a statistically significant difference.

\section{Results}

Protein and mRNA expression levels of Livin are markedly decreased in Livin-knockdown HCT116 and SW620 cell lines. To confirm the effect of Livin knockdown in HCT116 and SW620 cell lines, the protein and mRNA expression levels of Livin were evaluated by western blot analysis and RT-qPCR, respectively. Western blot analysis indicated that Livin was significantly down regulated in the shLivin group, compared with in the NC and control groups, in HCT116 and SW620 cells. $\beta$-actin was used as the loading control. All western blotting results are representative of at least three independent experiments (Fig. 1A and B). Ratios between Livin to actin in the shLivin group were significantly lower compared with the control or NC groups (Fig. 1C and D). Band densitometries were evaluated using ImageJ as aforementioned, expression level comparisons of Livin and actin were compared using two-way analysis of variance $(\mathrm{P}<0.05$, shLivin group vs. control or NC groups). In addition, a marked inhibition of Livin mRNA expression was observed in the shLivin group compared with in the $\mathrm{NC}$ and control groups $(\mathrm{P}<0.05$, shLivin group vs. control or NC groups; Fig. 1E and F). Each bar represents the mean $\pm \operatorname{SD}(n=3)$.

Silencing Livin increases the chemotherapeutic sensitivity of colon cancer cells to 5-FU. AO-EB staining was performed to 
A

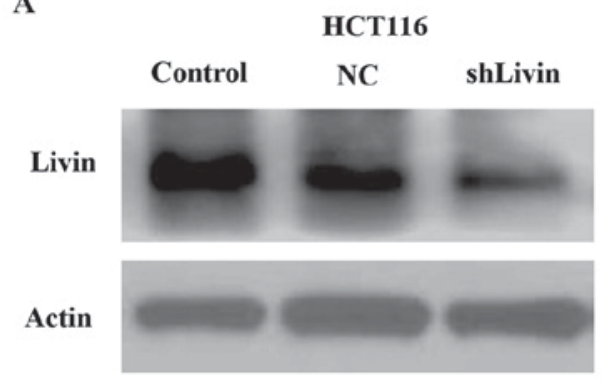

C

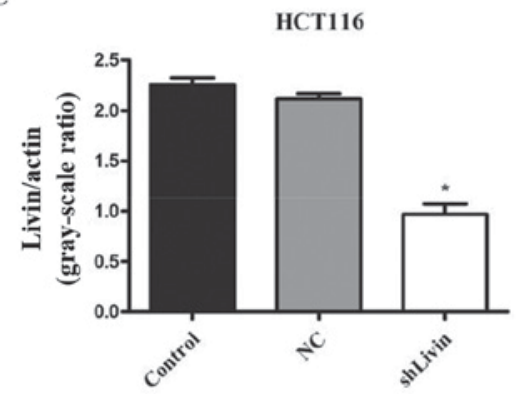

E

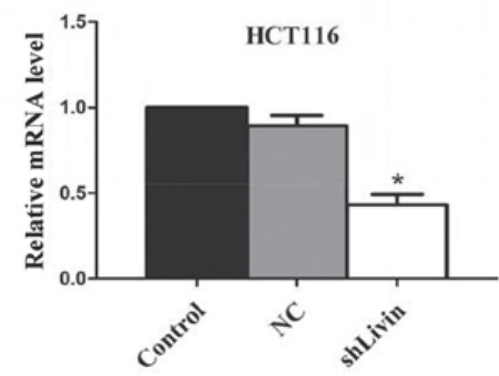

B

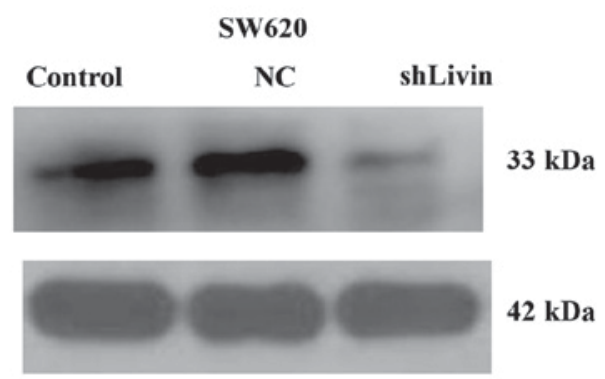

D

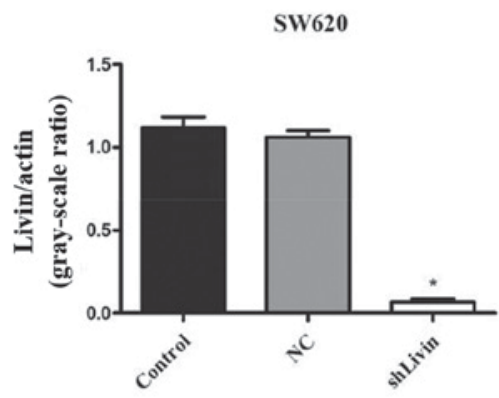

F

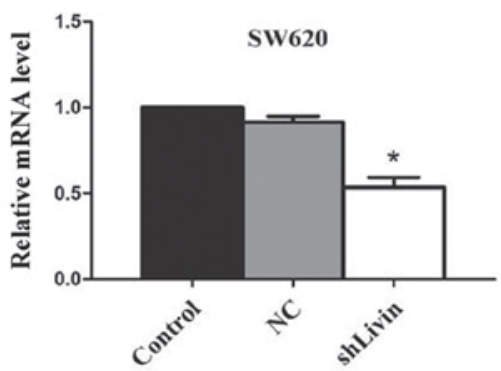

Figure 1. Monitoring the transfection efficiency of Livin in colon cancer cells by western blotting and reverse transcription-quantitative polymerase chain reaction. Western blot analysis indicated that Livin was downregulated in the shLivin group, compared with in the NC and control groups, in (A) HCT116 and (B) SW620 cell lines. Livin densitometry was evaluated using ImageJ, expression level comparisons of Livin and actin were compared by two-way analysis of variance $(\mathrm{C}$ and $\mathrm{D})$. The relative expression levels of Livin mRNA in the shLivin group were markedly inhibited, compared with in the NC and control groups, in (E) HCT116 and (F) SW620 cell lines. Each bar represents the mean \pm standard deviation (n=3). "P<0.05, compared with the control or NC groups. NC, negative control; shLivin, lentivirus-short hairpin Livin.

confirm that silencing Livin increased the chemotherapeutic sensitivity of colon cancer cells to 5-FU. Following treatment with 5-FU $(20 \mu \mathrm{M})$ for $24 \mathrm{~h}$, higher level of granular yellow-green nuclear AO staining and concentrated orange nuclear EB staining, were detected in the shLivin group compared with the control or NC groups (Fig. 2A). This indicated a higher level of apoptosis. The cell death rate of shLivin group was significantly higher compared with those of the control and NC groups $(\mathrm{P}<0.05$; Fig. $2 \mathrm{~B})$. These results confirmed that silencing Livin enhanced 5-FU sensitivity in HCT116 and SW620 cell lines.

To further investigate the effect of Livin knockdown on the response of colon cancer cells to 5-FU, the LDH assay was performed. The present study revealed that the shLivin group had a significantly higher cell toxicity compared with the control and $\mathrm{NC}$ groups, which indicated participation of Livin in 5-FU-induced cell death $(\mathrm{P}<0.05$; Fig. 2C).

Cell viability was evaluated by a CCK- 8 assay. Concentrations of 5-FU that resulted in a 50\% growth inhibition are indicated as the $\mathrm{IC}_{50}$ values (Fig. 2D). In the HCT116 cells, the $\mathrm{IC}_{50}$ of the shLivin, NC and control groups after $24 \mathrm{~h}$ were $19.733 \pm 4.127$, $35.323 \pm 4.356$ and $39.380 \pm 3.628 \mu \mathrm{M}$, respectively. In the SW620 cell line, the $\mathrm{IC}_{50}$ of the shLivin, $\mathrm{NC}$ and control groups after $24 \mathrm{~h}$ were $32.537 \pm 3.925,56.880 \pm 3.082$ and $61.120 \pm 2.661 \mu \mathrm{M}$, respectively. The $\mathrm{IC}_{50}$ of the shLivin group was significantly lower, compared with those of the control and NC groups $(\mathrm{P}<0.05$; Fig. 2D). Data are presented as the mean $\pm \mathrm{SD}$ of three experiments.

Blockade of autophagy or apoptosis inhibits Livin knockdown-induced recovery of 5-FU sensitivity in HCT116 and SW620 cells. To further confirm the involvement of autophagy and apoptosis in Livin knockdown-induced HCT116 and SW620 cell death, the autophagy inhibitor 3-MA, and the apoptosis inhibitor Z-VAD-FMK, were used to investigate whether Livin knockdown-induced cell death may be attributed to autophagy and apoptosis. Following Lv-sh Livin transfection into HCT-116 and SW620 cells, 3 mM 3-MA was added $2 \mathrm{~h}$ prior to $24 \mathrm{~h}$ of $5-\mathrm{FU}(20 \mu \mathrm{M})$ treatment. Cell viability was evaluated with a CCK-8 assay; the $\mathrm{IC}_{50}$ values of pretreated groups were significantly increased to $26.583 \pm 3.387$ and $46.027 \pm 4.832 \mu \mathrm{M}$ in HCT-116 and SW620 cell lines, respectively, which was significantly increased compared with the non-pretreated shLivin group $(\mathrm{P}<0.05$; Fig. 2D). Similarly, 
A
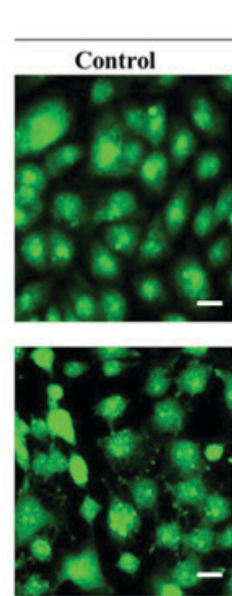

C

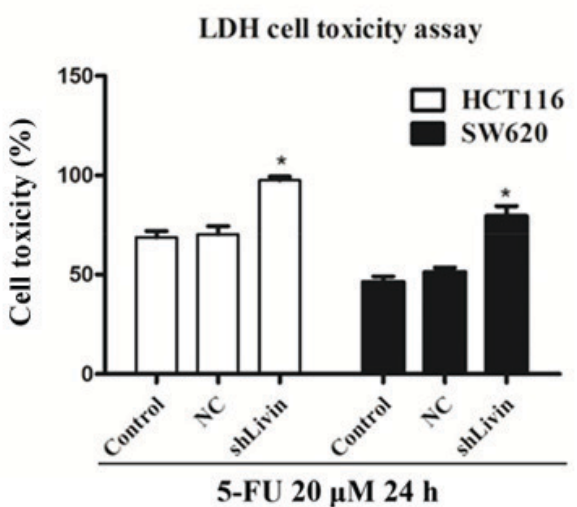

B

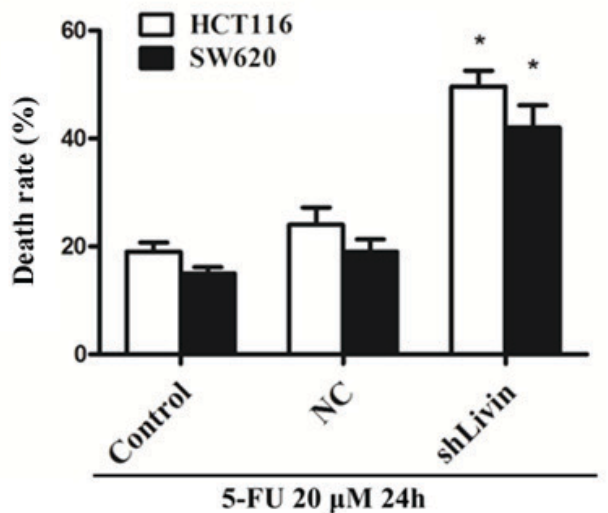

D

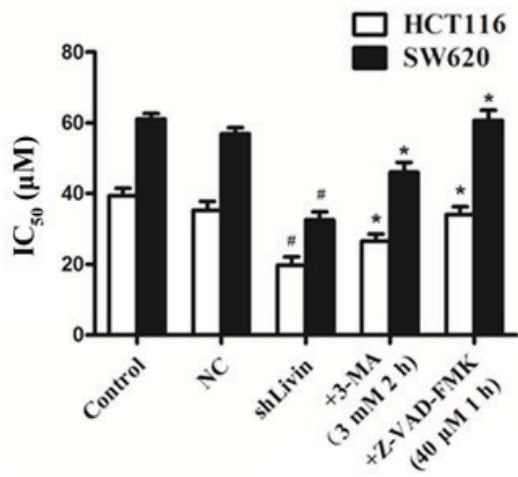

Figure 2. Silencing Livin increased the 5-FU sensitivity of colon cancer cells. (A) Acridine orange-ethidium bromide staining was performed following treatment with 5-FU $(20 \mu \mathrm{M})$ for $24 \mathrm{~h}$. A greater number of stress granules were observed in the cytoplasm of the shLivin group compared with in the control and NC groups. Images are obtained fluorescence microscopy (magnification, x200). Scale bar, $100 \mu \mathrm{m}$. The results are representative of $\geq 3$ independent experiments. (B) The cell death rate (\%) was determined as the percentage of positively stained cells. The cell death rate in the shLivin group was significantly high, compared with those of the control and NC groups, following treatment with 5-FU $(20 \mu \mathrm{M})$ for $24 \mathrm{~h}(\mathrm{P}<0.05$, shLivin group vs. control or NC groups). (C) Results of the LDH assay for the shLivin group compared with the control and NC groups. Silencing Livin improved 5-FU chemotherapy sensitivities of HCT-116 and SW0620 cell lines ("P<0.05, shLivin group vs. control or NC groups). (D) The $\mathrm{IC}_{50}$ of the shLivin group was significantly lower compared with the control and $\mathrm{NC}$ groups $\left({ }^{\#} \mathrm{P}<0.05\right.$, shLivin group vs. control or $\mathrm{NC}$ groups). The $\mathrm{IC}_{50}$ of $3-\mathrm{MA}$ and $\mathrm{Z}-\mathrm{VAD}-\mathrm{FMK}$ pretreated groups were significantly increased compared with the non-pretreated shLivin group due to the inhibition of autophagy and apoptosis, respectively ("P<0.05). All data are presented as the mean \pm standard deviation derived from triplicate samples from three independent experiments. 5-FU, 5-fluorouracil; $\mathrm{IC}_{50}$, half-maximal inhibitory concentration; NC, negative control; shLivin, lentivirus-short hairpin Livin.

Z-VAD-FMK $(40 \mu \mathrm{M})$ was added to the culture for $1 \mathrm{~h}$ prior to 5 -FU treatment; the $\mathrm{IC}_{50}$ of pretreated groups were raised to $34.053 \pm 3.913$ and $60.703 \pm 5.001 \mu \mathrm{M}$ in the HCT-116 and SW620 cells, respectively, which was significantly increased compared with in the non-pretreated shLivin group ( $\mathrm{P}<0.05$; Fig. 2D). Data are presented as the mean \pm SD from three repeated experiments. Inhibitor pretreatments markedly abrogated Livin knockdown-induced cell death, which indicated that autophagy and apoptosis contributed to Livin knockdown-induced 5-FU sensitivity recovery in HCT-116 and SW620 cells.

Silencing Livin induces the upregulation of apoptosis and autophagy in HCT116 and SW620 cells. Western blot analysis was performed to determine the expression levels of autophagic and apoptotic markers in the control, $\mathrm{NC}$ and shLivin groups (Fig. 3A). The ratio of LC3-II to LC3-I, an established indicator of autophagy, was markedly enhanced in the shLivin group, compared with in the control and NC groups. Conversely, P62 remained at a lower level in the shLivin group compared with in the control and NC groups (Fig. 3B-D).
Caspase-3 and SMAC, crucial executioners of apoptosis, were highly upregulated following Livin silencing, which indicated that apoptosis is upregulated by Livin down regulation $(\mathrm{P}<0.05$; Fig. $3 \mathrm{C}$ and $\mathrm{D})$. These results indicated an induction of apoptosis and autophagy mediated by Livin silencing. To confirm the activation of autophagy, the ultrastructure of cells was observed with electron microscopy (Fig. 4A and B). A markedly higher number of autophagosomes were observed in the shLivin group compared with in the control and NC groups (Fig. 4A). Quantification of autophagosomes from 12 random fields of view in three independent experiments revealed that a significantly higher number of autophagosomes in shLivin group compared with the control and NC groups $(\mathrm{P}<0.05$; Fig. 4B).

Inhibition of the Bcl-2 and Akt signaling pathways is involved in cell death induced by Livin silencing. Previous studies have demonstrated that $\mathrm{Bcl}-2$ can regulate autophagy and apoptosis due to cooperation with a number of substances, including $\mathrm{Ca}^{2+}$ and autophagy protein 5 (Atg5) (23). The Search Tool 
A

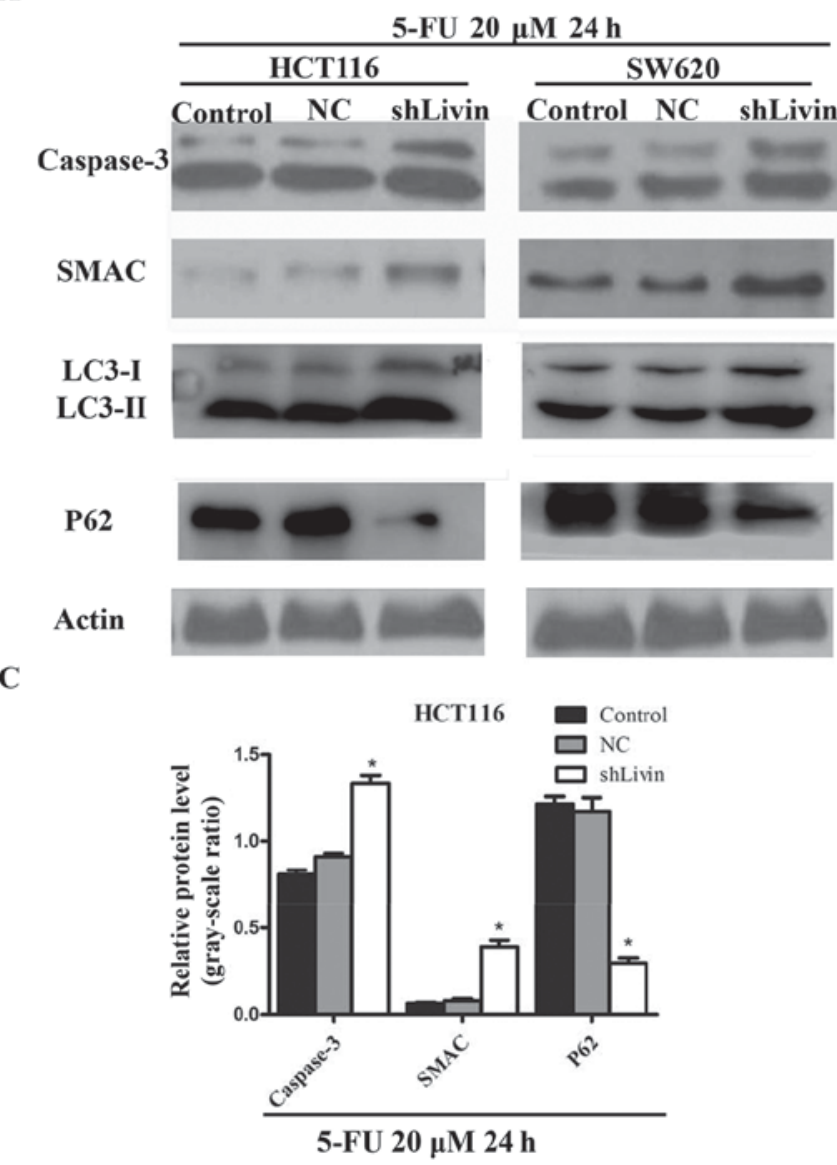

B

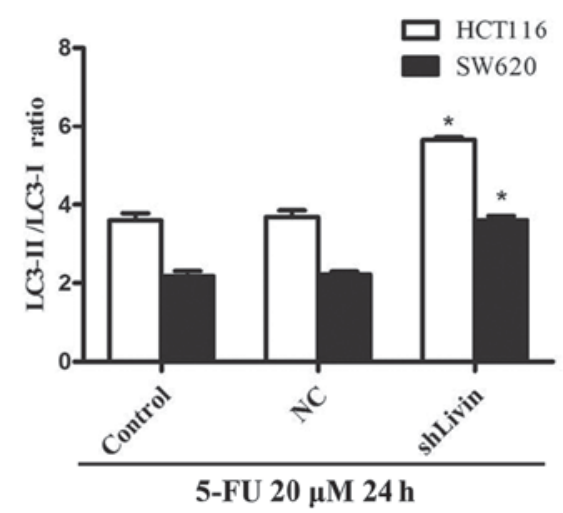

D

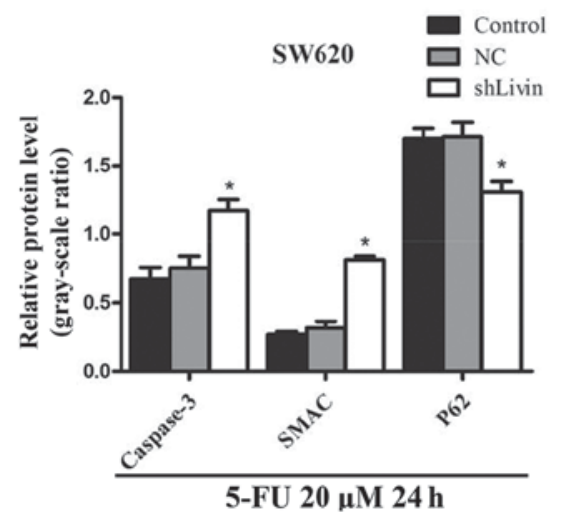

Figure 3. Western blot analysis of apoptosis and autophagy-associated proteins. (A) HCT116 and SW620 cells were incubated with $20 \mu \mathrm{M} 5$-FU for $24 \mathrm{~h}$, harvested and subjected to western blot analysis. The ratio of LC3-II/LC-I was increased in the shLivin group compared with in the control and NC groups. (B) The expression levels of caspase-3 and SMAC were higher in the shLivin group compared with in the control and NC groups in (C) HCT 116 and (D) SW620 cell lines, whereas protein expression level of p62 was decreased in the shLivin group compared with in the control and NC groups in (C) HCT 116 and (D) SW620 cell lines. These results indicated significantly higher levels of apoptosis and autophagy in the shLivin groups compared with in the control and $\mathrm{NC}$ groups. The data are presented as the mean \pm standard deviation of three independent experiments conducted under the same conditions $\left({ }^{*} \mathrm{P}<0.05\right.$, shLivin group vs. control or $\mathrm{NC}$ groups). 5-FU, 5-fluorouracil; $\mathrm{IC}_{50}$, half-maximal inhibitory concentration; $\mathrm{NC}$, negative control; shLivin, lentivirus-short hairpin Livin; SMAC, Schizont membrane-associated cytoadherence protein; LC3, light chain 3.

A

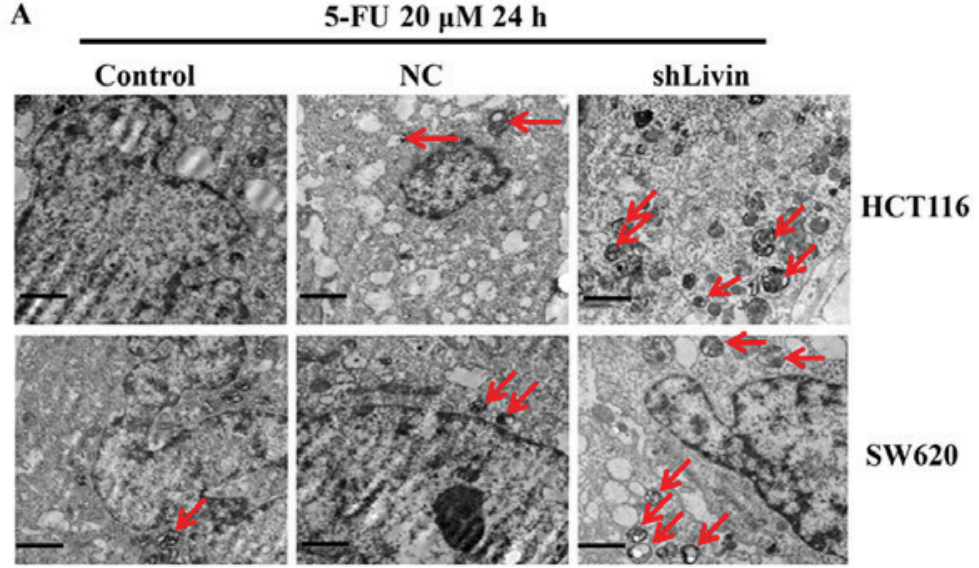

B

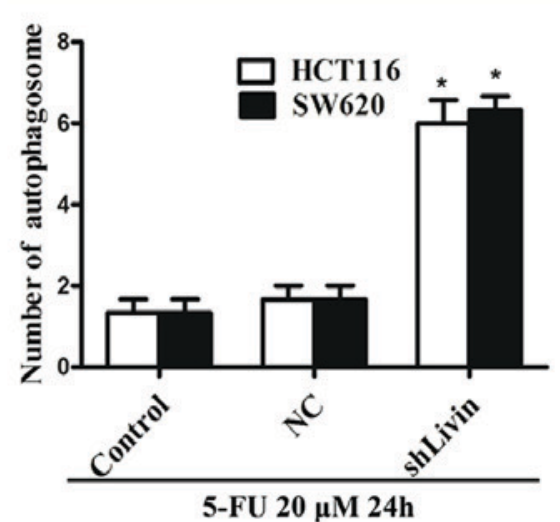

Figure 4. Representative transmission electron microscopic images of autophagosomes. (A) A markedly higher number of autophagosomes (red arrows) were observed in the shLivin group compared with in the control and NC groups. Images were obtained at magnification x15,000. Scale bar, $5 \mu \mathrm{m}$. (B) Quantification of autophagosomes in 12 random fields of view from three independent experiments are presented. " $\mathrm{P}<0.05 \mathrm{vs}$. the control or $\mathrm{NC}$ groups. NC, negative control; shLivin, lentivirus-short hairpin Livin.

for the Retrieval of Interacting Genes/Proteins analysis revealed Livin and associated protein-protein interactions in the literature (confidence mode; http://string-db.org/). Livin, and the autophagy/apoptosis markers Bcl-2 and Akt, were 
A

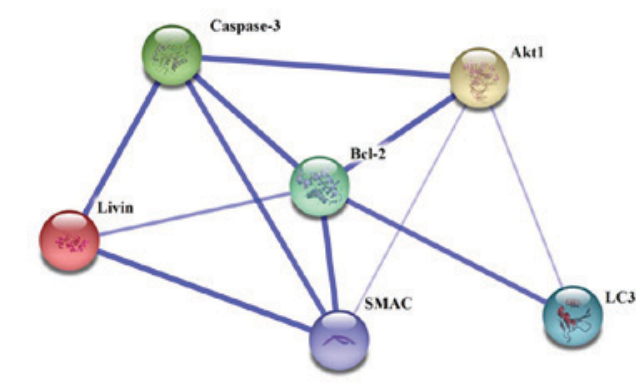

C

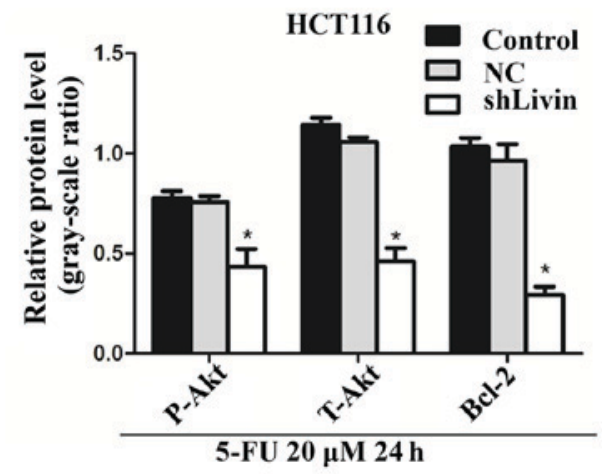

B

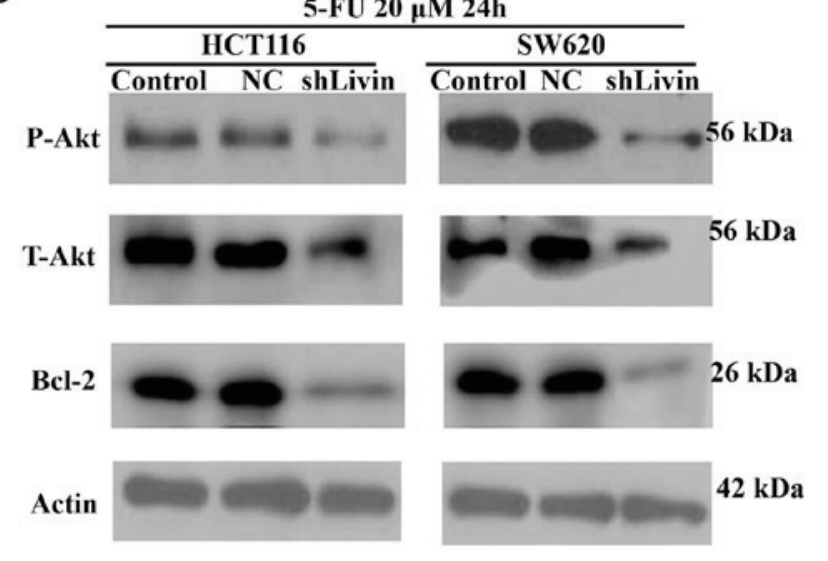

D

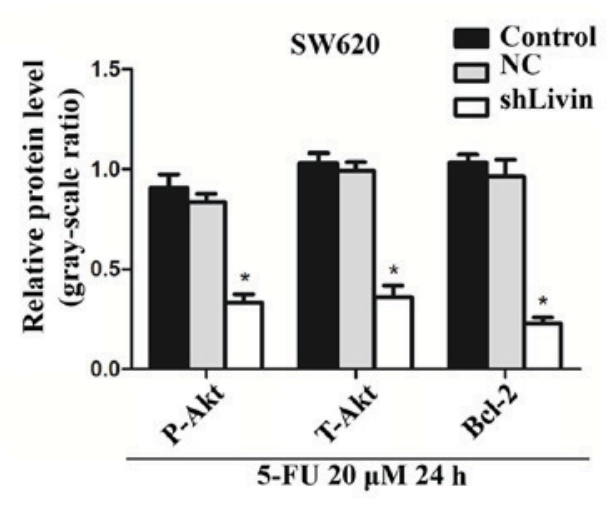

Figure 5. Inhibition of Bcl-2 and the Akt signaling pathway were involved in silenced-Livin-induced cell death. (A) STRING analysis revealed Livin and associated protein-protein interactions (confidence mode; http://string-db.org/). Within this cluster, Bcl-2 and Akt, which were located in the key nodes and mutually interacted, were selected for further analysis. (B) HCT116 and SW620 cells were incubated with $20 \mu \mathrm{M} 5$-FU for $24 \mathrm{~h}$, harvested and subjected to western blot analysis to detect the protein expression level of Bcl-2, p-Akt and T-Akt from the control, NC and shLivin groups. Images are representative of three independent experiments. Histograms represent p-Akt, T-Akt and Bcl-2 protein expression levels quantified by western blotting and the optical analysis software ImageJ in (C) HCT116 and (D) SW620 cells ("P<0.05, shLivin group vs. control or NC groups). Data are presented as the mean \pm standard deviation of three independent experiments. Bcl-2, B-cell lymphoma-2; LC3, light chain 3; SMAC, Schizont membrane-associated cytoadherence protein; Akt1, protein kinase B 1; p, phosphorylated; T, total; NC, negative control; shLivin, lentivirus-short hairpin Livin; STRING, Search Tool for the Retrieval of Interacting Genes/Proteins; 5-FU, 5-fluorouracil.

input into STRING and a main cluster was formed. Blue lines represent interactions between proteins, and line thickness denotes the confidence level associated with each interaction. Within this cluster, Bcl-2 and Akt, located in the key nodes and interact with each other, were selected for further analysis (Fig. 5A). Western blot analysis was performed to detect the expression levels of $\mathrm{Bcl}-2$, p-Akt and T-Akt in the control, $\mathrm{NC}$ and shLivin groups (Fig. 5B). The results indicated that silencing Livin decreased the expression levels of $\mathrm{Bcl}-2$ and Akt $(\mathrm{P}<0.05$; Fig. 5C and D). These results suggested the involvement of Bcl-2 and the Akt signaling pathway in cell death induced by Livin silencing. Bcl-2 and the Akt signaling pathway may serve key roles in regulating the crosstalk involved in silenced-Livin-induced apoptosis and autophagy.

\section{Discussion}

Livin is a crucial factor that contributes to therapeutic resistance in various tumor types (37). Previous studies have proposed Livin as a potential therapeutic target, owing to its high expression level and association with tumor pathology and outcome (38). A previous study investigated the expression levels of Livin in four colon cancer cell lines and revealed that the overexpression of Livin inhibited the activation of apoptosis in the chemotherapy-resistant cells (39). The present study confirmed that silencing Livin may improve sensitivity to 5-FU chemotherapy. The downregulation of Livin induced a high level of cell death, as revealed by AO-EB staining. Furthermore, it was demonstrated that this cell death was induced by apoptosis and autophagy. To the best of our knowledge, no previous experiments have been performed to analyze the association between Livin and the autophagic cell death of colon cancer cells when treated with 5-FU.

Self-destructive cell processes, namely autophagy and apoptosis, have been the focus of numerous researchers. Cell apoptosis serves an important role in suppressing cancer cell proliferation, which is involved in the activation of catabolic enzymes in particular proteases in the signaling cascade and leads to the rapid destruction of cellular structures and organelles (40). Previous studies have revealed that the apoptosis-associated gene Livin can regulate tumor cell apoptosis induced by chemotherapy (41). The present study demonstrated the upregulation of caspase-3 following Livin knockdown, which revealed that silencing Livin enhanced the sensitivity of colon cancer cells to 5-FU, leading to apoptosis. The use of the IAP (Z-VAD-FMK) indicated that the $\mathrm{IC}_{50}$ of 
SVI-shLivin cells significantly increased following inhibition of apoptosis by Z-VAD-FMK. These results indicated that silencing Livin improved the sensitivity of colon cancer cells to 5-FU, resulting in apoptosis.

Autophagy is initially induced to allow cells to adapt to stress; however, it also induces cell death in certain cases (42). Previous studies indicated that autophagy may be stimulated by numerous forms of cellular stresses, including nutrient or growth factor deprivation and hypoxia $(43,44)$. Conversely, certain studies suggested that autophagy may kill cancer cells via cellular digestion caused by lysosomal enzymes $(45,46)$. The results of the present study are consistent with the latter hypothesis. The expression levels of autophagy-associated proteins were detected via western blotting. The results indicated an increase in LC3-II, and a decrease in LC3-I, P62 and Bcl-2 expression levels in shLivin group compared with control and NC groups. Electron microscopy was used to observe the appearance of autophagosomes. The results indicated that there was a markedly increased number of autophagosomes in the shLivin group, compared with in the control and NC groups, which indicated that autophagy was promoted by silencing Livin. To further confirm the involvement of autophagic cell death, the inhibitor of autophagy, 3-MA, was added. The results demonstrated that the $\mathrm{IC}_{50}$ of SVI-shLivin cells was significantly increased following the inhibition of autophagy. These results implied that silencing Livin enhanced the sensitivity of colon cancer cells to 5-FU, leading to autophagic cell death.

The mechanisms underlying apoptosis and autophagy vary, and the functional association/crosstalk between them is complex (25). A previous study revealed that Bcl-2 can regulate autophagy and apoptosis due to cooperation with numerous substances, including $\mathrm{Ca}^{2+}$ and Atg5, which may be involved in oncogenesis and tumor progression (23). Based on the aforementioned information, and on the co-participation of autophagic cell death and apoptosis in the silenced-Livin-induced 5-FU sensitivity improvement, Bcl-2 expression was evaluated in the Livin-silenced cells. The result demonstrated a significant decrease in $\mathrm{Bcl}-2$ protein expression level. Certain previous studies confirmed the involvement of the Akt signaling pathway in the induction of autophagy $(47,48)$. The expression level of Akt was detected by western blotting to verify whether it was involved in the cell death induced by Livin silencing. The results indicated that Akt expression was significantly decreased due to Livin knockdown. The present study investigated the involvement of Bcl-2 and the Akt signaling pathway. Future studies are required to investigate the specific mechanism underlying the decrease in Bcl-2 and Akt expression induced by Livin silencing, and to explore the crosstalk between autophagic cell death and apoptosis processes regulated by $\mathrm{Bcl}-2$ and Akt.

\section{Acknowledgements}

Not applicable.

\section{Funding}

The present study was supported by the Shandong Key Research and Development Project (grant nos. 2014GSF118134 and 2015GSF118055), the Medicine and Healthcare Technology Development Project of Shandong Province (grant no. 2014WS0341), the Natural Science Foundation of Shandong Province (grant nos. BS2010YY060, ZR2014HM111 and ZR2014HP105) and the National Natural Science Foundation of China (grant no. 81602227).

\section{Availability of data and materials}

The datasets generated and analyzed in the present study are included in this published article.

\section{Authors' contributions}

CSL designed the experiments; SL and XL performed the experiments and analyzed the data. QL, HJL, YLS, HQZ and HJZ gave technical support and conceptional advice for the experiment and data analysis. SL and XL wrote the manuscript in consultation with QL, HJL, YLS, HQZ and HJZ. All authors approved the final manuscript.

\section{Ethics and consent to participate}

Not applicable.

\section{Consent for publication}

Not applicable.

\section{Competing interests}

The authors declare that they have no competing interests.

\section{References}

1. Greenlee RT, Hill-Harmon MB, Murray T and Thun M: Cancer statistics, 2001. CA Cancer J Clin 51: 15-36, 2001.

2. Saunders M and Iveson T: Management of advanced colorectal cancer: State of the art. Br J Cancer 95: 131-138, 2006.

3. Liu M, Liao M, Dai C, Chen JF, Yang CJ, Liu M, Chen ZG and Yao MC: Sanguisorba officinalis L synergistically enhanced 5-fluorouracil cytotoxicity in colorectal cancer cells by promoting a reactive oxygen species-mediated, mitochondria-caspasedependent apoptotic pathway. Sci Rep 6: 34245, 2016.

4. He S, Zhao Z, Yang Y, O'Connell D, Zhang X, Oh S, Ma B, Lee JH, Zhang T, Varghese B, et al: Truncating mutation in the autophagy gene UVRAG confers oncogenic properties and chemosensitivity in colorectal cancers. Nat Commun 6: 7839, 2015.

5. Zhang H, Tang J, Li C, Kong J, Wang J, Wu Y, Xu E and Lai M: MiR-22 regulates 5-FU sensitivity by inhibiting autophagy and promoting apoptosis in colorectal cancer cells. Cancer Lett 356: 781-790,2015.

6. Nachmias B, Ashhab Y and Ben-Yehuda D: The inhibitor of apoptosis protein family (IAPs): An emerging therapeutic target in cancer. Semin Cancer Biol 14: 231-243, 2004.

7. Endo T, Abe S, Seidlar HB, Nagaoka S, Takemura T, Utsuyama M, Kitagawa M and Hirokawa K: Expression of IAP family proteins in colon cancers from patients with different age groups. Cancer Immunol Immunother 53: 770-776, 2004.

8. Liu B, Han M, Wen JK and Wang L: Livin/ML-IAP as a new target for cancer treatment. Cancer Lett 250: 168-176, 2007.

9. Xi RC, Biao WS and Gang ZZ: Significant elevation of survivin and livin expression in human colorectal cancer: Inverse correlation between expression and overall survival. Onkologie 34: 428-432, 2011.

10. Myung DS, Park YL, Chung CY, Park HC, Kim JS, Cho SB, Lee WS, Lee KH, Lee JH and Joo YE: Expression of Livin in colorectal cancer and its relationship to tumor cell behavior and prognosis. PLoS One 8: e73262, 2013. 
11. Zhuang L, Shen LD, Li K, Yang RX, Zhang QY, Chen Y, Gao CL, Dong C, Bi Q, Tao JN, et al: Inhibition of livin expression suppresses cell proliferation and enhances chemosensitivity to cisplatin in human lung adenocarcinoma cells. Mol Med Rep 12: 547-552, 2015.

12. Ding ZY, Zhang H, Adell G, Olsson B and Sun XF: Livin expression is an independent factor in rectal cancer patients with or without preoperative radiotherapy. Radiat Oncol 8: 281, 2013.

13. Longley DB, Harkin DP and Johnston PG: 5-Fluorouracil: Mechanisms of action and clinical strategies. Nat Rev Cancer 3: 330-338, 2003.

14. Grem JL: 5-Fluorouracil: Forty-plus and still ticking. A review of its preclinical and clinical development. Invest New Drugs 18 299-313, 2000

15. Wang X, Xu J, Ju S, Ni H, Zhu J and Wang H: Livin gene plays a role in drug resistance of colon cancer cells. Clin Biochem 43: 655-660, 2010

16. Liang SR, Hu GR, Fang LJ, Huang SJ, Li JS, Zhao MY and Meng MJ: CpG oligodeoxynucleotides enhance chemosensitivity of 5-fluorouracil in HepG2 human hepatoma cells via downregulation of the antiapoptotic factors survivin and livin. Cancer Cell Int 13: 106, 2013.

17. Green DR: Apoptotic pathways: Ten minutes to dead. Cell 121 671-674, 2005

18. Sui X, Jin L, Huang $X$, Geng $S$, He C and Hu X: p53 signaling and autophagy in cancer: A revolutionary strategy could be developed for cancer treatment. Autophagy 7: 565-571, 2011.

19. Sui X, Kong N, Wang X, Fang Y, Hu X, Xu Y, Chen W, Wang K, Li D, Jin W, et al: JNK confers 5-fluorouracil resistance in p53-deficient and mutant p53-expressing colon cancer cells by inducing survival autophagy. Sci Rep 4: 4694, 2014.

20. Baehrecke EH: Autophagy: Dual roles in life and death? Nat Rev Mol Cell Biol 6: 505-510, 2005.

21. Lum JJ, DeBerardinis RJ and Thompson CB: Autophagy in metazoans: Cell survival in the land of plenty. Nat Rev Mol Cell Biol 6: 439-448, 2005

22. Mizushima N, Levine B, Cuervo AM and Klionsky DJ: Autophagy fights disease through cellular self-digestion. Nature 451: 1069-1075, 2008

23. Zhou F, Yang Y and Xing D: Bcl-2 and Bcl-xL play important roles in the crosstalk between autophagy and apoptosis. FEBS J 278: 403-413, 2011.

24. Yang J and Yao S: JNK-Bcl-2/Bcl-xL-Bax/Bak pathway mediates the crosstalk between matrine-induced autophagy and apoptosis via interplay with Beclin 1. Int J Mol Sci 16: 25744-25758, 2015

25. Maiuri MC, Zalckvar E, Kimchi A and Kroemer G: Self-eating and self-killing: Crosstalk between autophagy and apoptosis. Nat Rev Mol Cell Biol 8: 741-752, 2007.

26. Cheng Y, Ren X, Zhang Y, Patel R, Sharma A, Wu H, Robertson GP, Yan L, Rubin E and Yang JM: eEF-2 kinase dictates cross-talk between autophagy and apoptosis induced by Akt inhibition, thereby modulating cytotoxicity of novel Akt inhibitor MK-2206. Cancer Res 71: 2654-2663, 2011.

27. Elbashir SM, Harborth J, Weber K and Tuschl T: Analysis of gene function in somatic mammalian cells using small interfering RNAs. Methods 26: 199-213, 2002.

28. McManus MT and Sharp PA: Gene silencing in mammals by small interfering RNAs. Nat Rev Genet 3: 737-747, 2002.

29. Overbergh L, Kyama CM, Valckx D, Debrock S, Mwenda JM, Mathieu C and D'Hooghe T: Validation of real-time RT-PCR assays for mRNA quantification in baboons. Cytokine 31 454-458, 2005

30. Livak KJ and Schmittgen TD: Analysis of relative gene expression data using real-time quantitative PCR and the 2(-Delta Delta C(T)) method. Methods 25: 402-408, 2001

31. Hirano S: Western blot analysis. Methods Mol Biol 926: 87-97, 2012.

32. Janes KA: An analysis of critical factors for quantitative immunoblotting. Sci Signal 8: rs2, 2015.
33. Zhang J, Guo H, Zhang H, Wang H, Qian G, Fan X, Hoffman AR, $\mathrm{Hu}$ JF and Ge S: Putative tumor suppressor miR-145 inhibits colon cancer cell growth by targeting oncogene friend leukemia virus integration 1 gene. Cancer 117: 86-95, 2011.

34. Yu J, Li X, Tashiro S, Onodera S and Ikejima T: Bcl-2 family proteins were involved in pseudolaric acid B-induced autophagy in murine fibrosarcoma L929 cells. J Pharmacol Sci 107: 295-302, 2008

35. An WW, Wang MW, Tashiro S, Onodera S and Ikejima T: Norcantharidin induces human melanoma A375-S2 cell apoptosis through mitochondrial and caspase pathways. J Korean Med Sci 19: 560-566, 2004

36. Kasibhatla S, Amarante-Mendes GP, Finucane D, Brunner T, Bossy-Wetzel E and Green DR: Acridine orange/ethidium bromide (AO/EB) staining to detect apoptosis. CSH Protoc 2006: pdb.prot4493, 2006

37. Wang R, Lin F, Wang X, Gao P, Dong K, Zou AM, Cheng SY, Wei SH and Zhang HZ: Silencing Livin gene expression to inhibit proliferation and enhance chemosensitivity in tumor cells. Cancer Gene Ther 15: 402-412, 2008.

38. Miura K, Fujibuchi W, Ishida K, Naitoh T, Ogawa H, Ando T, Yazaki N, Watanabe K, Haneda S, Shibata C and Sasaki I: Inhibitor of apoptosis protein family as diagnostic markers and therapeutic targets of colorectal cancer. Surg Today 41: 175-182, 2011.

39. Ding ZY, Liu GH, Olsson B and Sun XF: Upregulation of the antiapoptotic factor Livin contributes to cisplatin resistance in colon cancer cells. Tumor Biol 34: 683-693, 2013.

40. Hannun YA: Apoptosis and the dilemma of cancer chemotherapy. Blood 89: 1845-1853, 1997

41. Lopes RB, Gangeswaran R, McNeish IA, Wang Y and Lemoine NR: Expression of the IAP protein family is dysregulated in pancreatic cancer cells and is important for resistance to chemotherapy. Int J Cancer 120: 2344-2352, 2007.

42. Codogno P and Meijer AJ: Autophagy and signaling: Their role in cell survival and cell death. Cell Death Differ 12 (Suppl 2): S1509-S1518, 2005.

43. Ogata M, Hino S, Saito A, Morikawa K, Kondo S, Kanemoto S, Murakami T, Taniguchi M, Tanii I, Yoshinaga K, et al: Autophagy is activated for cell survival after endoplasmic reticulum stress. Mol Cell Biol 26: 9220-9231, 2006.

44. Pietrocola F, Pol J, Vacchelli E, Baracco EE, Levesque S, Castoldi F, Maiuri MC, Madeo F and Kroemer G: Autophagy induction for the treatment of cancer. Autophagy 12: 1962-1964, 2016.

45. Gozuacik D and Kimchi A: Autophagy as a cell death and tumor suppressor mechanism. Oncogene 23: 2891-2906, 2004.

46. Bialik S and Kimchi A: Lethal weapons: DAP-kinase, autophagy and cell death. Curr Opin Cell Biol 22: 199-205, 2010.

47. Nakamura Y, Yogosawa S, Izutani Y, Watanabe H, Otsuji E and Sakai T: A combination of indole-3-carbinol and genistein synergistically induces apoptosis in human colon cancer HT-29 cells by inhibiting Akt phosphorylation and progression of autophagy. Mol Cancer 8: 100, 2009.

48. Li S, Chen JW, Xie X, Tian J, Deng C, Wang J, Gan HN and Li F: Autophagy inhibitor regulates apoptosis and proliferation of synovial fibroblasts through the inhibition of PI3K/AKT pathway in collagen-induced arthritis rat model. Am J Transl Res 9: 2065-2076, 2017

This work is licensed under a Creative Commons Attribution-NonCommercial-NoDerivatives 4.0 International (CC BY-NC-ND 4.0) License. 